\title{
Evaluation of the level of antibodies against Chlamydophila (Chlamydia) pneumoniae in post-surgery heart ischaemia patients and their clinical conditions - a six-year study
}

Mirosław Brykczyński', Andrzej Żych', Iwona Gorący², Iwona Mączyńska³, Iwona Wojciechowska-Koszko³, Krzysztof Mokrzycki', Stefania Giedrys-Kalemba ${ }^{3}$, Piotr Sielicki ${ }^{1}$

1Department of Cardiac Surgery, Pomeranian Medical University, Szczecin, Poland 2Department of Laboratory Diagnostics and Molecular Medicine, Pomeranian Medical University, Szczecin, Poland

${ }^{3}$ Department of Microbiology and Immunology, Pomeranian Medical University, Szczecin, Poland

Submitted: 3 July 2009

Accepted: 10 October 2009

Arch Med Sci 2010; 6. 2: 214-220

DOI: $10.5114 /$ aoms.2010.13898

Copyright @ 2010 Termedia \& Banach

\section{Abstract}

Introduction: Inflammatory conditions modulated by Chlamydophila (Chlamydia) pneumoniae are considered to play an important role in the onset of atherosclerosis. In this paper we present the results of progressive observation of $C$. pneumoniae antibody titres in patients who underwent coronary artery bypass graft (CABG).

Material and methods: The objective of our research was a prospective observation of antibody titres in IgA and IgG class antibodies against C. pneumoniae using indirect immunofluorescence in a group of 155 post-surgery CABG patients suffering from heart ischaemia. The microbiological test results were compared with patients' present coronary complaints evaluated on the CCS scale during a six-year period.

Results: Six years after CABG, 128 patients (82.6\%) are still alive. During the study a positive serological conversion of antibody titres was observed in 36 patients in the IgA class antibodies, and in 26 patients in the IgG class. The group of patients with no antibodies against $C$. pneumoniae decreased from 23.2 to $3.4 \%$, while the group of patients with antibodies in both IgG and IgA classes increased from 52.3 to $83.9 \%$. The average CCS degree decreased from 3.18 before CABG to 1.65 in the present study.

Conclusions: These results show no connection between the serological symptoms of chronic $C$. pneumoniae infection and coronary complaints evaluated on the CCS scale during a six-year study on post-CABG patients suffering from heart ischaemia. The surgical treatment of heart ischaemia brought about longterm improvement in the coronary condition of the observed group of patients.

Key words: atherosclerosis, Chlamydophila (Chlamydia) pneumoniae, coronary artery bypass graft, progressive examination.

\section{Introduction}

Damage of the endothelium is considered to be crucial in the onset of atherosclerosis. It leads to increase in T lymphocyte adhesion, release of numerous cytokines, and then to proliferation of smooth muscle. As a result of the process atherogenesis, atheromatosus plaque are formed. They cause limitation of the coronary reserve, which manifests as patients' coronary complaints. In addition to well-known, classical risk factors which

\section{Corresponding author:}

Mirosław Brykczyński, MD, PhD Department of Cardiac Surgery Pomeranian Medical University Al. Powstańców Wielkopolskich 72

70-111 Szczecin, Poland Phone: +48914661391

Fax: +48914661393

E-mail:

mirobryk@sci.pam.szczecin.pl 
can initiate the atherogenesis, some bacterial and viral infections are also considered to play a role in the aetiology of CAD. Chlamydophila pneumoniae (C. pneumoniae), responsible for atypical bronchitis and pneumonia, is in the range of interest of some researchers. A chronic C. pneumoniae infection shows a modulating influence on the development of atherosclerosis, thus increasing the level of independent risk factors for coronary disease, such as acute phase protein or LDL cholesterols [1-4]. Saikku et al. [5] were the first to notice the appearance of antibodies against $C$. pneumoniae in patients suffering from coronary artery disease and myocardial infarction. Thom et al. [6] in their paper showed that an elevated level of antibodies against C. pneumoniae increases the probability of development of coronary artery disease almost three times.

A common method of diagnosing C. pneumoniae-triggered-inflammations is to examine patient's serum for species-specific IgM, IgG and IgA class antibodies. Determining the dynamics of appearance and disappearance of particular immunoglobulin classes allows one to diagnose what kind of infections the patient suffers from: primary, chronic, or reinfection. In an acute primary infection, IgM class antibodies appear first and their levels remain increased for about 2 months, to gradually subside later. Next, the IgG class antibody titre levels increase, and then the same elevation is noticed in the IgA class. In case of successful treatment and no reinfection, the antibody levels slowly decrease, despite the fact that elevation in IgG class antibody levels is usually observed proportionally to the patient's age. Increased, but remaining stable, the level of IgG class antibodies, and, in particular, IgA class antibodies may indicate a chronic infection and/or frequently reoccurring infections [7].

The objective of this study was to compare the C. pneumoniae antibody levels in 118 patients treated surgically for coronary artery disease preoperatively and after six years of follow-up. In this study we also tried to evaluate the influence of $C$. pneumoniae infection on the late results of surgical treatment of CAD.

\section{Material and methods}

The study was conducted between 1999 and 2000 (2000 Study) and between 2005 and 2006
(2006 Study). Both studies were financed by the State Committee for Scientific Research from the Science and Research Fund: KBN 4P05C05815 and 2P05C03529.

For the 2000 Study 155 patients with diagnosed CAD caused by disseminated stenoses and scheduled for elective surgical treatment were chosen. All patients were operated on with extracorporeal circulation. Patients with poor ejection fraction, operated on emergently and with stenoses in one or two vessels were excluded from the study. The group consisted of 31 women (20\%), mean age $61.65 \pm 8.7$ years, and 124 men (80\%), mean age $56.36 \pm 8.9$ years. Their preoperative coronary complaints were evaluated according to the CCS scale $(8,9)$. Before the operation 2 patients (1.3\%) were in CCS class I, 19 patients (12.3\%) reported coronary pains in class II, and 81 patients (52.3\%) in class III. Fifty-three patients (34.2\%) reported pains at rest (CCS class IV). The average degree on the CCS scale in 155 patients was 3.13 . Ninety-two patients (59.4\%) had myocardial infarction in the past. The 2006 Study was conducted 6 years after the surgery (mean 83.4 months, \pm 3.6 ), on the same group of patients, and included laboratory and general examination. Risk factors for progression of atherosclerosis (e.g. diabetes, hypertension, smoking history, obesity, etc.) were the same, but more patients in the 2006 Study were on statins and antiaggregants. These values were not statistically significant. The antibody titres in IgG and IgA classes against C. pneumoniae were measured in those patients preoperatively and six years after the surgery using indirect immunofluorescence (Euroimmun, Germany). 1 : 50 solution for IgA class and $1: 100$ for IgG class was assumed to be positive (Table I). For the purpose of statistical analysis and avoidance of division into smaller groups, each titre value of antibodies was assigned a specific score. Depending on the dilution of solution in which the antibodies were detected, their corresponding titres were assigned a point score (Table II). Adding the scores for detecting antibodies in particular IgA and IgG antibody titres, we received qualification which allowed for a statistical analysis of the degree of C. pneumoniae infection in patients (Table III).

The data were completed for all 155 patients in the 2000 Study. 128 patients (82.5\%) were still alive, 27 patients (17.4\%) died, and 10 living patients

Table I. Classification of antibody titres against C. pneumoniae

\begin{tabular}{|cccccc|}
\hline \multicolumn{2}{|c}{ Antibodies against $C$. pneumoniae } & Score & \multicolumn{2}{c|}{ Antibodies against C. pneumoniae } & \multicolumn{1}{c|}{ Score } \\
\hline $\lg (-)$ & None & OA & $\operatorname{lgG}(-)$ & None & 0G \\
\hline $\lg \mathrm{A}(+)$ & $1: 50$ & AA & $\operatorname{lgG}(+)$ & $1: 100$ & $1 \mathrm{G}$ \\
\hline $\lg \mathrm{A}(+)$ & $1: 100$ & 2A & $\operatorname{lgG}(+)$ & $1: 1000$ & $2 \mathrm{G}$ \\
\hline
\end{tabular}


Table II. 2000 and 2006 Studies

\begin{tabular}{|lcccc|}
\hline Points & 0-1 (low titre) & $2-3$ (increased titre) & 4 (high titre) & Total \\
\hline 2000 Study & 66 & 65 & 24 & 155 \\
\hline Deaths & 16 & 7 & 4 & 27 \\
\hline No consent $^{\star}$ & 2 & 6 & 2 & 10 \\
\hline 2006 Study & 48 & 52 & 18 & 118 \\
\hline
\end{tabular}

*No consent for examination in 2006

Table III. Clinical interpretation of antibody titres against C. pneumoniae

\begin{tabular}{|lcc|}
\hline Points & Antibodies & Sum total of points \\
\hline $0-1$ & Low or lack of titre & $0 A+0 G$ or $1 \mathrm{~A}+0 \mathrm{G}$ or $0 \mathrm{~A}+1 \mathrm{G}$ \\
\hline $2-3$ & Increased titre & $\begin{array}{c}\mathrm{A}+1 \mathrm{G} \text { or } 2 \mathrm{~A}+0 \mathrm{G} \text { or } 0 \mathrm{~A}+2 \mathrm{G} \\
\text { or } 2 \mathrm{~A}+1 \mathrm{G} \text { or } 1 \mathrm{~A}+2 \mathrm{G}\end{array}$ \\
\hline 4 & High titre & $2 \mathrm{~A}+2 \mathrm{G}$ \\
\hline
\end{tabular}

(6.45\%) did not consent to participate in the control study.

Both studies were financed by the State Committee for Scientific Research from the Science and Research Fund: KBN 4P05C05815 and KBN 2P05C03529. Both studies were accepted by the Ethics Committee of the Pomeranian Medical University. Data were analysed using STATISTICA 6.0 software.

\section{Results}

The results of serological tests done preoperatively in 155 patients in the 2000 Study showed specific antibodies against $C$. pneumoniae in IgG class in 110 patients (71\%), and in IgA class in 90 patients (58,1\%). In 81 patients (52.3\%) antibodies in both IgA class (1:50 or $1: 100$ solutions) and IgG class ( $1: 100$ and $1: 1000$ solutions) were found. In 36 surgery patients $(23.22 \%)$ no antibodies in either of those classes were found.

Another titre assay and a comparative analysis with the previous results was conducted on 118 patients (Table IV). In the 2000 Study IgA and IgG class antibodies were found in 63 patients (53.39\%), but in the 2006 Study 99 patients (83.9\%) had those antibodies. The number of patients with IgA class antibodies increased from 69 (58.47\%) to 102 patients (86.4\%). In 36 patients (30.5\%) antibodies were found for the first time, and in 61 patients $(51.7 \%)$ an increase of their titre occurred $(p<0.001$ $-\chi^{2}$ test). Similarly, the number of patients with a positive test result for IgG class antibodies increased from 85 (72.03\%) to 111 patients (94.1\%). In 26 patients (22.0\%) IgG class antibodies were found for the first time, while in 47 patients (39.8\%) an increase of their titre occurred $\left(p<0.001-\chi^{2}\right.$ test). Only in 4 patients (3.38\%) were no antibodies in either IgA or IgG class found - compared to 27 patients $(22.88 \%)$ from the 2000 Study.

The growing frequency of occurrence of increased antibody titres was confirmed by the titre score evaluation in both 2000 and 2006 Studies (Table V). The mean titre score for IgA and IgG classes in the 2000 Study rose from 1.91 points to 2.99 points in the 2006 Study ( $p<0.001-\chi^{2}$ test). Respectively, we noted an increase in the antibody titres in IgA class from 0.89 to 1.57 and in the IgG class from 1.02 to 1.42 ( $p<0.05-\chi^{2}$ test). It should be emphasized that no acute infection symptoms

Table IV. Comparison of IgA and IgG class antibody levels in 118 patients

\begin{tabular}{|lccccccc|}
\hline Antibodies & \multicolumn{3}{c|}{ SCORE IgA } & \multicolumn{3}{c|}{ SCORE IgG } \\
\hline SCORE & OA & IA & 2A & OG & $1 \mathrm{G}$ & $2 \mathrm{G}$ \\
\hline 2000 Study & 49 & 33 & 36 & 33 & 50 & 35 \\
\hline 2006 Study & 16 & 19 & 83 & 7 & 55 & 56 \\
\hline
\end{tabular}

Table V. Score qualification of antibody titres in patients in 2000 and 2006 Studies

\begin{tabular}{|lcccc|}
\hline Points & $0-1$ (low titer) & $2-3$ (increased titer) & 4 (high titer) & Total \\
\hline 2000 Study & 48 & 52 & 18 & 118 \\
\hline 2006 Study & 15 & 54 & 49 & 118 \\
\hline
\end{tabular}


were present at the time of the test in any of the patients. Half of the surveyed patients had an episode of respiratory tract infection within 12 months preceding the monitoring test for antibodies against $C$. pneumoniae (Table VI). Thirty patients were treated with antibiotics for various reasons within a year preceding the test. In 18 patients the reason for antibiotic treatment was respiratory tract infections. The patients with the highest titre levels of antibodies against $C$. pneumoniae were the ones who had been most frequently treated with antibiotics.

The analysis of intensification of coronary complaints during a six-year follow-up period as compared to the elevated levels of titres of antibodies against $C$. pneumoniae is presented in Table VII. In the 2000 Study 2 patients (1.3\%) reported no coronary complaints (CCS class I), coronary pains in CCS class II were reported by 12 patients (12.3\%), while 67 patients (52.3\%) had complaints in CCS class III. The rest of anginal episodes (CCS class IV) were reported by 37 patients (34.2\%). Mean complaint degree on the CCS scale was 3.17.

In the 2006 Study, 54 patients (45.8\%) did not report any significant coronary complaints (CCS class I). 54 patients (45.8\%) reported class II coronary complaints; 7 patients (5.9\%) in class III and only 3 patients (2.5\%) were in class IV. In all the groups, regardless of the level of antibodies against C. pneumoniae, a statistically significant decrease of CCS degree was noted ( $p<0.05$ nonparametric test - the sign test) (Table VIII). A significant decrease in the coronary complaints does not mean that those patients did not require intensive medical care. Fifty eight patients (49.2\%) were admitted to hospital for cardiological reasons during the study period, including 10 patients (8.5\%) admitted due to recent myocardial infarction. Another 10 patients (8.5\%) were admitted to hospital due to cerebral ischaemia symptoms. The mean length of stay for the group of 58 patients was 2.9 (Table IX).

Twenty seven deaths (17.4\%) including 5 women (16.1\%), mean age 67.4 years ( \pm 9.4 years), and 22 deaths among men (17.7\%), mean age 62.1 years ( \pm 9.6 years), occurred in the study period. The mean age of the deceased was $63.1 \pm 9.6$ years. Three patients $(1.9 \%)$ died in the postoperative period and another 4 (2.6\%) during two months following the surgery. Other patients from this group died

Table VI. Infections in respiratory tract and/or antibiotic treatment during the study

\begin{tabular}{|lccccc|}
\hline Points & 0-1 (low titre) & 2-3 (increased titre) & 4 (high titre) & Total & Value of $p$ \\
\hline 2006 Study & 15 & 54 & 49 & 118 & ns \\
\hline Respiratory tract infections [\%] & 46.7 & 44.4 & 57.1 & 50.0 & ns \\
\hline Infection + antibiotic [\%] & 6.7 & 7.4 & 26.5 & 15.2 & 0.02 \\
\hline Antibiotic treatment [\%] & 13.3 & 22.2 & 32.6 & 25.4 & ns \\
\hline
\end{tabular}

Table VII. Increase in coronary complaints during a six-year period following CABG

\begin{tabular}{|c|c|c|c|c|c|}
\hline & Points & 0-1 (low titre) & 2-3 (increased titre) & 4 (high titre) & Total \\
\hline \multirow[t]{10}{*}{2000 Study } & Number of patients & 48 & 52 & 18 & 118 \\
\hline & CCS 1 & 1 & 1 & 0 & 2 \\
\hline & $\operatorname{CCS} 2$ & 3 & 6 & 3 & 12 \\
\hline & $\operatorname{CCS} 3$ & 26 & 33 & 8 & 67 \\
\hline & CCS 4 & 18 & 12 & 7 & 37 \\
\hline & Euroscore* $^{*}$ & $2.97 \pm 1.3$ & $3.48 \pm 2.2$ & $3.05 \pm 1.4$ & $3.21 \pm 1.8$ \\
\hline & Number of bypasses & 3.73 & 3.88 & 4.11 & 3.85 \\
\hline & Arterial bypasses & 1.77 & 1.48 & 1.83 & 1.65 \\
\hline & Venous bypasses & 1.96 & 2.40 & 2.28 & 2.20 \\
\hline & Points & $0-1$ (low titre) & 2-3 (increased titre) & 4 (high titre) & Total \\
\hline \multirow[t]{5}{*}{2006 Study } & Number of patients & 15 & 54 & 49 & 118 \\
\hline & $\operatorname{CCS} 1$ & 10 & 23 & 21 & 54 \\
\hline & $\operatorname{CCS} 2$ & 5 & 24 & 25 & 54 \\
\hline & $\operatorname{CCS} 3$ & 0 & 5 & 2 & 7 \\
\hline & $\operatorname{CCS} 4$ & 0 & 2 & 1 & 3 \\
\hline
\end{tabular}

${ }^{*}$ Kruskal-Wallis test $(p=n s)$ 
Table VIII. Improvement by 1, 2, 3 CCS classes, no change or exacerbation (0) within 6 years after CABG in the investigated groups in both studies

\begin{tabular}{|c|c|c|c|c|c|c|c|c|c|c|c|c|c|c|}
\hline \multirow{3}{*}{\multicolumn{2}{|c|}{$\begin{array}{l}2000 \text { CCS I-III } \\
(N=81)\end{array}$}} & \multicolumn{12}{|c|}{2006} & \\
\hline & & \multicolumn{4}{|c|}{ 0-1 (low titre) } & \multicolumn{4}{|c|}{ 2-3 (increased titre) } & \multicolumn{4}{|c|}{4 (high titre) } & \\
\hline & & -2 & -1 & 0 & 1 & -2 & -1 & 0 & 1 & -2 & -1 & 0 & 1 & \\
\hline \multirow[t]{3}{*}{2000} & $0-1$ & 2 & 3 & 2 & 0 & 8 & 7 & 0 & 0 & 2 & 5 & 3 & 0 & $p^{*}=0.07$ \\
\hline & $2-3$ & 1 & 1 & 0 & 0 & 7 & 10 & 1 & 0 & 5 & 8 & 2 & 1 & $p^{*}=\mathrm{NS}$ \\
\hline & 4 & 0 & 0 & 0 & 0 & 1 & 3 & 0 & 0 & 2 & 4 & 2 & 1 & $p^{\star *}=N S$ \\
\hline \multirow{3}{*}{\multicolumn{2}{|c|}{$\begin{array}{l}2000 \text { CCS IV } \\
(n=37)\end{array}$}} & \multicolumn{12}{|c|}{2006} & \\
\hline & & \multicolumn{4}{|c|}{ 0-1 (low titre) } & \multicolumn{4}{|c|}{ 2-3 (increased titre) } & \multicolumn{4}{|c|}{4 (high titre) } & \\
\hline & & -1 & -2 & -3 & 0 & -1 & -2 & -3 & 0 & -1 & -2 & -3 & 0 & \\
\hline \multirow[t]{3}{*}{2000} & $0-1$ & 2 & 3 & 0 & 0 & 3 & 4 & 1 & 0 & 2 & 0 & 0 & 1 & $p^{*}=\mathrm{NS}$ \\
\hline & $2-3$ & 0 & 1 & 0 & 0 & 3 & 2 & 0 & 2 & 5 & 3 & 0 & 0 & $p^{*}=\mathrm{NS}$ \\
\hline & 4 & 0 & 0 & 0 & 0 & 1 & 1 & 0 & 0 & 2 & 1 & 0 & 0 & $p^{\star *}=\mathrm{NS}$ \\
\hline
\end{tabular}

${ }^{*}$ Kruskal-Wallis test, **Mann-Whitney $U$ test

Table IX. Complications occurring during a six-year study

\begin{tabular}{|c|c|c|c|c|c|}
\hline Score & 0-1 (low titre) & 2-3 (increased titre) & 4 (high titre) & Total & Value of $p$ \\
\hline Number of patients & 15 & 54 & 49 & 118 & ns \\
\hline Myocardial infarction before 2000 & 10 & 37 & 28 & 75 & ns \\
\hline Another myocardial infarction after 2000 & 1 & 3 & 6 & 10 & ns \\
\hline Stroke after 2000 & 3 & 2 & 5 & 10 & ns \\
\hline Admitted to hospital after 2000 & 7 & 31 & 20 & 58 & ns \\
\hline Length of stay & 4 & 2.7 & 2.6 & 2.9 & ns \\
\hline
\end{tabular}

${ }^{*}$ Kruskal-Wallis test

between 9 and 76 months following the surgery (the mean number of months following the surgery was 51). The most frequent cause of death was coronary condition. Obtaining reliable medical documentation for some of the deceased was not always possible. In two cases (7.4\%) the direct cause of death was cancer, and in another two (7.4\%) cerebral stroke.

The most deaths, i.e. 16 (24.2\%), occurred in those patients who in the 2000 Study had no antibodies or low-titre antibodies in one class only (0-1 points) $(p<0.05-$ sign test). However, all three post-surgery deaths (0-30 days) occurred in this group. But they were caused by cardiac insufficiency, and not by a chronic infection. Respectively, in the increased titre group 7 deaths $(10.8 \%)$ occurred, and 4 deaths (16.7\%) in the high titre group (Table II). These correlations, however, were not statistically significant in our research.

\section{Discussion}

It has been over ten years since the first papers on the coexistence of $C$. pneumoniae chronic infection symptoms and atherosclerotic disease were published. There exist over 800 publications on the subject, but none offers a definite answer as to what function and impact this infection has in the atherosclerotic disease pathogenesis. Although, as of today, there is no incontrovertible evidence which would clearly indicate a direct connection between the onset of arthrosclerosis and $C$. pneumoniae inflammation, many researchers are inclined to agree with the theory that a chronic bacterial inflammation modulates the process of atherogenesis. Strachan et al. [10] published data indicating a relationship between $C$. pneumoniae infection and a higher mortality rate in coronary artery disease for persons with an elevated level of IgA class antibodies. Similarly, Lindholt et al. [11] in their research showed elevated titres in IgA class antibodies in abdominal aortic aneurysm patients. Anzini et al. [12] researched the influence of C. pneumoniae infection on ischaemic stroke in young patients (aged 18-46 years) and concluded that the elevated titre in IgA class antibodies was significantly higher than in the control group. Zairis et al. [13] found a relationship between chronic c. pneumoniae infection and progression of 
atherosclerosis in patients who underwent coronary artery stent implantation. The diagnostic criteria for chronic C. pneumoniae infection are not clearly defined. Some researchers focus on the titre of IgA class antibodies; others suggest that taking into account both IgA and IgG antibodies would provide a more complete diagnostic picture. Yet, regardless of which diagnostic method we favour, the proper interpretation criteria for assaying antibody titre must be defined. The system we used allowed for a more objective analysis of antibodies in both classes with their varying titres. The onset and progression of atherosclerosis is conditioned by the presence and expression of many risk factors. Some of them are modifiable, e.g. the cholesterol level or body weight; others, such as coexisting diabetes or renal insufficiency, may be regulated by an efficient therapy. Some other factors, such as age, increase the risk with the passing of time. Thus when studying the influence of the titre of antibodies against $C$. pneumoniae and their late effect, we should be aware of other factors whose impact on the final result is not always possible to estimate. The death of a patient during follow-up seems to be a victory of the disease over the applied treatment plan. The highest, statistically significant mortality occurred in the group of patients who either had no antibodies against $C$. pneumoniae or whose titres in one of the groups was low. To some extent, the fact could be blamed on their mean age, which was 2.4 years higher than in the group of surviving patients. The observations we made seem to accord with the research results published by Martinez et al. [14]. They reported that an increase in titres of antibodies against $C$. pneumoniae positively correlated with increasing mean age of the study group. Particularly important is that, in our research, we combined long-term observation of post-CABG patients with observation of the occurrence of positive conversion of the titres of antibodies against $C$. pneumoniae. In the group with a high antibody titre we did not find a significant negative serum conversion, which may indicate a reinfection and/or a chronic inflammatory process caused by $C$. pneumoniae. The number of patients who had symptoms of $C$. pneumoniae infection was significantly higher between the ages of 50 and 75 than in other such studies [14-16]. The analysis of the population of patients suffering from coronary artery disease indicates a higher number of C. pneumoniae infections and a greater extent of its development than in a population not affected by heart ischaemia. Evaluation of the degree of coronary complaints in postoperative patients assessed on the CCS scale showed a significant improvement in all the groups. In patients with especially intensified coronary complaints before CABG the reoccurrence of coronary complaints after
CABG depends on both degeneration processes in the grafts and the development of alterations in the patients' own blood vessels. Our study does not confirm the observations of other scientists who describe a parallel increase in the coronary complaints along with the increasing frequency of high titres of antibodies against $C$. pneumoniae. On the contrary, the group with the highest titre of antibodies against C. pneumoniae from the 2006 Study reported the least reoccurrence of coronary complaints. Our observations are contrary to those of Gurfinkel et al. [17], which suggested that an increase in the titres of antibodies against C. pneumoniae is related to the intensification of coronary complaints and is observed more frequently in patients suffering from acute coronary syndrome. Frequent acute infections of patients' upper and lower respiratory tract during the observation period indicate a greater probability of becoming infected by this common bacterium. It was noted that respiratory tract infections as well as antibiotic treatment were more frequent in the group with the highest antibody titre than in the remaining groups. As a result of antibiotic treatment, the inflammatory process in the endothelium may become temporarily suppressed, regardless of the factors which cause that condition. It appears that the role CP infection plays in progression of atherosclerotic disease is not as significant as the role other coexisting risk factors might play, particularly in cases where an intensive multimodal treatment is applied.

In conclusion:

1) the results of the research indicate a lack of association between a chronic C. pneumoniae infection and intensification of coronary complaints evaluated on the CCS scale in patients with CAD treated surgically during a sixyear observation period;

2) microbiological test results indicate increasing frequency of the occurrence of high titres of antibodies against $C$. pneumoniae during the follow-up after surgical treatment of CAD;

3) surgical treatment of coronary artery disease brought long-term relief in coronary complaints.

\footnotetext{
References

1. Gibbs RG, Carey N, Davies AH. Chlamydia pneumoniae and vascular disease. Br J Surg 1998; 85: 1191-7.

2. Toss H, Gnarpe J, Gnarpe H, Siegbahn A, Lindahl B, Wallentin L. Increased fibrinogen levels are associated with persistent Chlamydia pneumoniae infection in unstable coronary artery disease. Eur Heart J 1998; 19: 570-7.

3. Laurila A, Bloigu A, Näyhä S, Hassi J, Leinonen M, Saikku P. Chronic Chlamydia pneumoniae infection is associated with a serum lipid profile known to be a risk factor for atherosclerosis. Arterioscler Thromb Vasc Biol 1997; 17: 2910-3.
} 
4. Anderson JL, Carlquist JF, Muhlestein JB, Horne BD, Elmer SP. Evaluation of $\mathrm{C}$-reactive protein, an inflammatory marker, and infectious serology as risk factors for coronary artery disease and myocardial infarction. J Am Coll Cardiol 1998; 32: 35-41.

5. Saikku P, Leinonen M, Mattila K, et al. Serological evidence of an association of a novel Chlamydia, TWAR, with chronic coronary heart disease and acute myocardial infarction. J Lancet 1988; 29: 983-6.

6. Thom DH, Grayston JT, Siscovick DS, Wang SP, Weiss NS, Daling JR. Association of prior infection with Chlamydia pneumoniae and angiographically demonstrated coronary artery disease. JAMA 1992; 268: 68-72.

7. Brykczyński M. Ocena wpływu leczenia roksytromycyną przewlekłych zakażeń Chlamydia pneumoniae u chorych operowanych z powodu choroby niedokrwiennej serca [Polish]. Rozprawa habilitacyjna. Pomorska Akademia Medyczna, Szczecin, 2001 Suppl. 64.

8. Campeau L Letter: Grading of angina pectoris. Circulation 1976; 54: 522-3.

9. Goldman L, Hashimoto B, Cook EF, Loscalzo A. Comparative reproducibility and validity of systems for assessing cardiovascular functional class: advantages of a new specific activity scale. Circulation 1981; 64: 1227-34.

10. Strachan DP, Carrington D, Mendall MA, et al. Relation of Chlamydia pneumoniae serology to mortality and incidence of ichaemic heart disease over 13 years in the caerphilly prospective heart disease study. BMJ 1999; 318: 1035-9.

11. Lindholt JS, Støvring J, Østergaard L, et al. Serum antibodies against Chlamydia pneumoniae outer membrane protein cross-react with the heavy chain of immunoglobulin in the wall of abdominal aortic aneurysms. Circulation 2004; 109: 2097-102.

12. Anzini A, Cassone A, Rasura M, et al. Chlamydia pneumoniae infection in young stroke patients: a casecontrol study. Eur I Neurol 2004; 11: 321-7.

13. Zairis MN, Papadaki OA, Psarogianni PK, et al. Serologic markers of persistent Chlamydia pneumonia infection and long-term prognosis after successful coronary stenting. Am Heart J 2003; 146: 1082-9.

14. Martínez MA, Kogan R, Silva JJ, Pinto ME, Vidal C, Huppo H. Seroprevalence of Chlamydia pneumoniae in Chile. Scand J Infect Dis 1999; 31: 103-4.

15. Koivisto AL, Isoaho R, Von Hertzen L, et al. Chlamydial antibodies in an elderly Finnish population. Scand J Infect Dis 1999; 31: 135-9.

16. Gnarpe J, Gnarpe H, Gause-Nilsson I, Lundorg P, Steen B. Seroprevalence of antibodies to Chlamydia pneumoniae in elderly people: a two-decade longitudinal and cohort difference study. Scand J Infect Dis 2000; 32: 177-9.

17. Gurfinkel E, Bozovich G, Beck E, Testa E, Livellara B, Mautner B. Treatment with the antibiotic roxithromycin in patients with acute non-Q-wave coronary syndromes. The final report of the ROXIS Study. Eur Heart J 1999; 20: 121-7. 